\title{
Enhanced retention of a maxillofacial prosthetic obturator using precision attachments: Two case reports
}

\author{
Sema Murat ${ }^{1}$ \\ Ayhan Gurbuz \\ Abulfaz Isayev ${ }^{1}$ \\ Bahadir Dokmez ${ }^{1}$ \\ Unsun Cetin ${ }^{1}$
}

\section{ABSTRACT}

The majority of maxillary defects can be rehabilitated with conventional simple obturator prosthesis. However, inadequate retention, stability and support may be associated with the use of an obturator. Precision attachments have been used to retain obturators for some time. The use of precision attachments in a dentate maxillectomy patient can yield significant functional improvement while maintaining the obturator's aesthetic advantages. This clinical report describes the prosthetic rehabilitation of two maxillary defects with an obturator retained using extracoronal resilient precision attachments. (Eur J Dent 2012;6:212-217)

Key words: Obturator; retention; precision attachment

This case report was presented at the $14^{\text {th }}$ Congress of the Balkan Stomatological Society (BaSS), Varna, BULGARIA, May 2009.

\section{INTRODUCTION}

Surgical and prosthetic rehabilitation can offer functional and aesthetic improvements to postmaxillectomy patients. Despite advances in surgical procedures, surgical reconstruction of maxillectomy defects is not always possible because of the general health condition of the patient. ${ }^{1}$ In addition, the ability to monitor the defect for recurrence is lost and mucous tends to accumulate on

1 Department of Prosthodontics, Faculty of Dentistry, Ankara University, Ankara, TURKIYE

- Corresponding author: Dr. Sema Murat Ankara Universitesi, Dishekimligi Fakultesi, Protetik Dis Tedavisi AD. Besevler Ankara, TURKIYE Tel: + 903122965555

Fax: + 903122123954

Email: semamurat47ayahoo.com.tr the nasal side of the flap causing unpleasant odors and local infections. ${ }^{2}$ Obturators can be used for either temporary or permanent rehabilitation. ${ }^{3-5}$ Fabrication of an obturator prosthesis offers the possibility of immediate and adequate dental rehabilitation. Moreover, the prosthesis can be easily removed to examine the surgical site so that tumor recurrence may be detected in a timely manner.

The primary goal of prosthetic obturation is closure of the maxillectomy defect and separation of the oral cavity from the sino-nasal cavities in order to prevent hyper-nasal speech and liquid leakage into the nasal cavity. ${ }^{6-9}$ The prosthesis should also improve mastication, swallowing, articulation and speech intelligibility, restore facial contours and reduces drooling. ${ }^{5,10-13}$ Failure of prosthetic treatment is often related to the retentive proper- 
ties of the prosthesis. Retention is affected by a variety of factors, including the level of direct/indirect retention promoted by the remaining teeth; defect size; available tissue surrounding the cavity; and muscular control. ${ }^{14}$ Stability and esthetics also contribute to treatment success in terms of improvements in the patient's social life. ${ }^{15,16}$

The majority of maxillary defects can be rehabilitated with a conventional simple obturator prosthesis that uses various clasps as retention components. ${ }^{17-19}$ In many cases, however, a conventional obturator prosthesis is unable to provide adequate retention, stability and support. In such cases, precision attachments may be very useful. The use of multiple attachments has been described as providing increased stability and retention of the prosthesis, as well as improved water and air tightness. ${ }^{20}$ The use of attachments as an adjunct to maxillary obturators is indicated for (a) improved aesthetics and (b) improved retention in comparison to conventional clasping on incisors as terminal abutments adjacent to a large defect., ${ }^{7,20}$

These two clinical reports describe the prosthetic rehabilitation of maxillary defects using an obturator with extracoronal resilient attachments used in place of retentive buccal clasps.

\section{FIRST CASE REPORT}

A 65-year-old man was referred by his head and neck surgeon to the Department of Prosthodontics at the Ankara University, Faculty of Dentistry in Ankara, Turkey for an evaluation for prosthetic treatment. The patient's major complaints were lack of retention and instability of the prosthesis, impaired speech and mastication, and liquid leakage into the oral cavity. Five years earlier, the patient had been diagnosed with epidermoid carci-

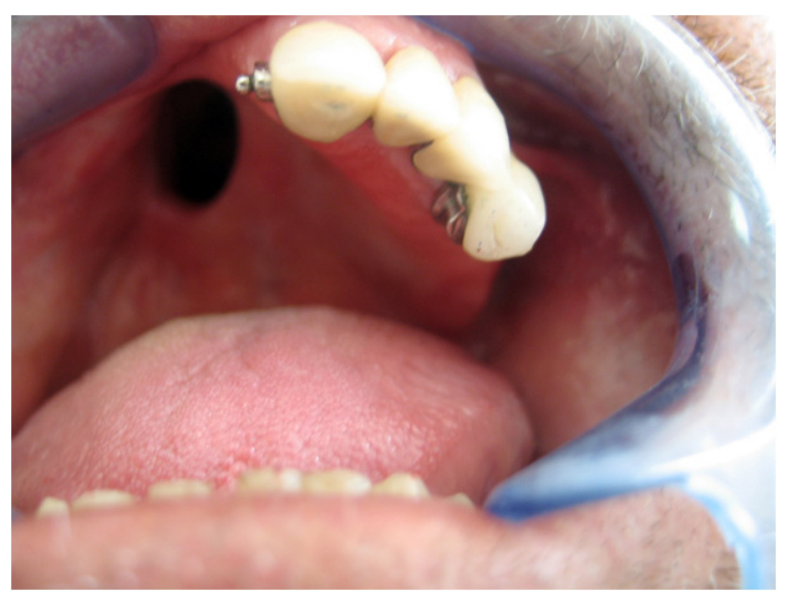

Figure 1. Intraoral view of patient. noma of the maxillary sinus that was treated by a unilateral maxillectomy followed by post-surgical radiation therapy. As a result of surgery and radiotherapy, the patient had experienced fibrosis and scar contraction, and after 4 years of successful treatment with a conventional obturator prosthesis, he presented with an ill-fitting obturator that was no longer retentive. Extra-oral examination revealed a collapsed midface and diplopia. Intraoral examination showed resectioning of the hard palate, alveolar bone, teeth and soft tissue that did not exceed the midline. The patient had 4 viable maxillary teeth (left central incisor, left lateral incisor, left canine and left first premolar) and mild periodontal disease. The defect was classified according to Aramany as a Class I Curved Arch Form. ${ }^{17}$

The obturator framework was designed according to Kennedy Class I RPD design principles, including tooth support, placement of direct retainer adjacent to the defect extension base, and indirect retention. ${ }^{11,21}$ The obturator was retained using extracoronal resilient attachments so that retentive buccal clasps were not required.

All remaining teeth were splinted using a 4-unit metal-ceramic fixed partial denture (FDP) to distribute the anticipated obturator stresses. Resilient extra-coronal ball attachments (Servo Dental, Hagen Halden, Germanyl were placed at the left central incisor and left first premolar for direct retention (Figure 1). Rest seats were prepared to direct the forces along the long axes of the abutments and reduce wear on the attachment. 50 A primary impression was made using irreversible impression material (Soft Hydrogum, Zhermack, Rovigo, Italy) and poured in Type III dental stone (Dentstone; Pankaj Industries, Mumbai, India). A custom-made tray was constructed from auto-polymerizing acrylic resin according to a predetermined outline on the stone model, a secondary impression was made from polyvinyl siloxane (Xantopren M mucosa; Heraeus Kulzer, Hanau, Germanyl in order to develop a definitive cast on which the obturator framework would be designed (Figure 2). The definite cast was then examined in order to re-evaluate the obturator path of insertion, after which the obturator framework was waxed on the refractory cast. The framework pattern was cast in base-metal alloy, finished and polished (Figure 3), and evaluated intraorally. Oc-

April 2012 - Vol.6 
clusal relationship were secured and mounted in a semi-adjustable articulator. Teeth position and occlusion were checked, and the necessary corrections were made before processing the dentures. A closed, hollow-bulb obturator prosthesis was processed from heat-polymerizing acrylic resin using conventional laboratory procedures. (Lucitone 199; Dentsply, Austenal, New York) (Figure 4) and delivered (Figure 5). The obturator portion of the prosthesis was smoothed to reduce the possibility of trauma to the mucosa and thus improve tolerance of the prosthesis.

The patient was provided with oral hygiene instruction, and follow-up evaluations were performed at 3 and 6 months. At the 1-year recall visit, the patient reported that the obturator prosthesis was comfortable and easy to maintain.

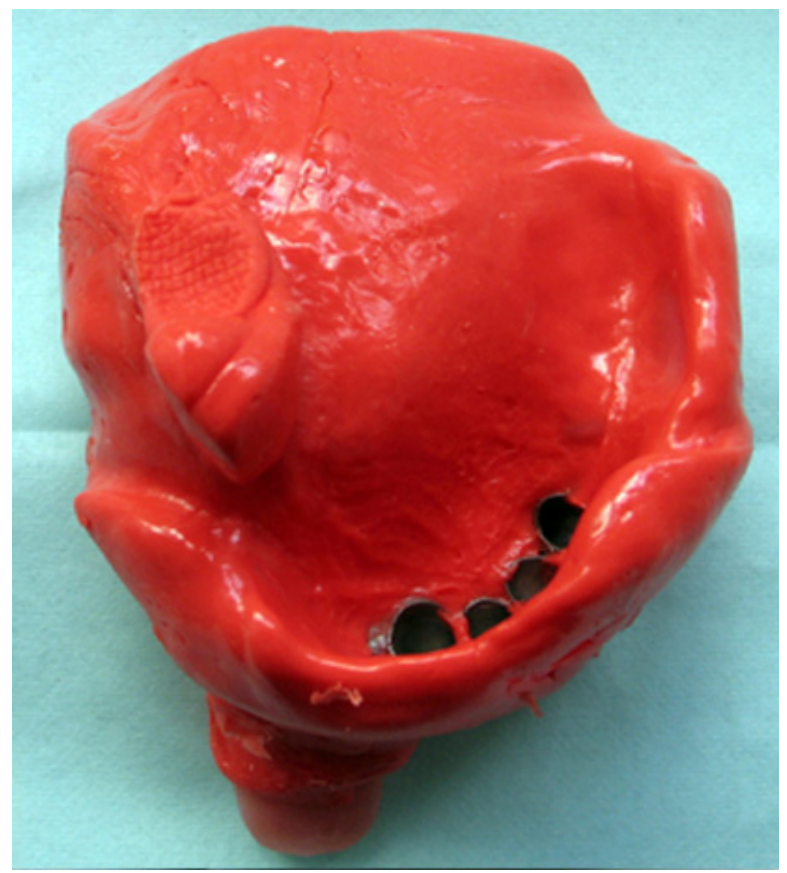

Figure 2. Final impression.

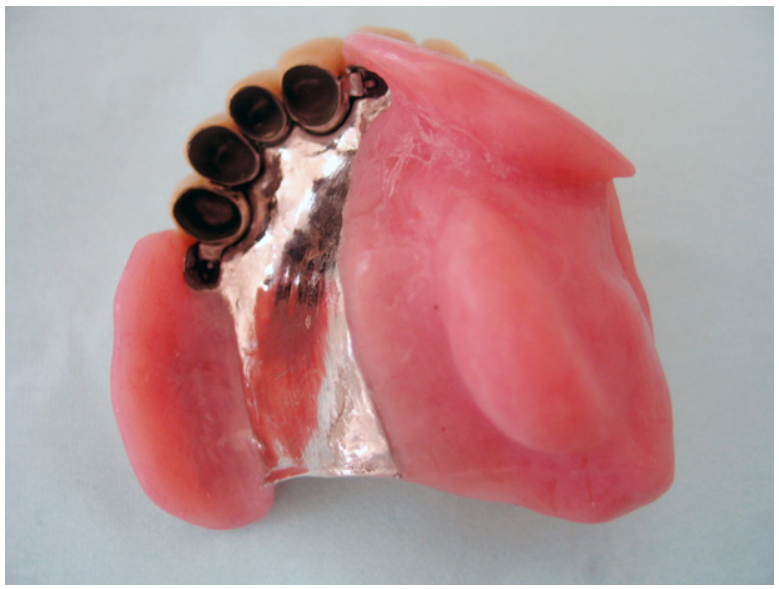

Figure 4. Processed prosthesis

\section{SECOND CASE REPORT}

A 36-year-old man was referred to the Department of Prosthodontics at the Ankara University, Faculty of Dentistry in Ankara, Turkey for prosthetic rehabilitation. His primary concerns were poor facial appearance, impaired speech and regurgitation of food into the nasal cavity. The patient had undergone a bilateral partial maxillectomy following the diagnosis of squamous cell carcinoma of the maxillary sinus. Treatment did not include chemotherapy or radiotherapy. Clinical examination revealed a maxillofacial defect extending from the premaxilla to the right first molar, left canine and hard palate. The defect was classified according to Aramany as a Class VI Curved Arch Form. ${ }^{17}$ The patient's post-surgery maxillary dentition consisted of 6 maxillary teeth lleft canine, left second

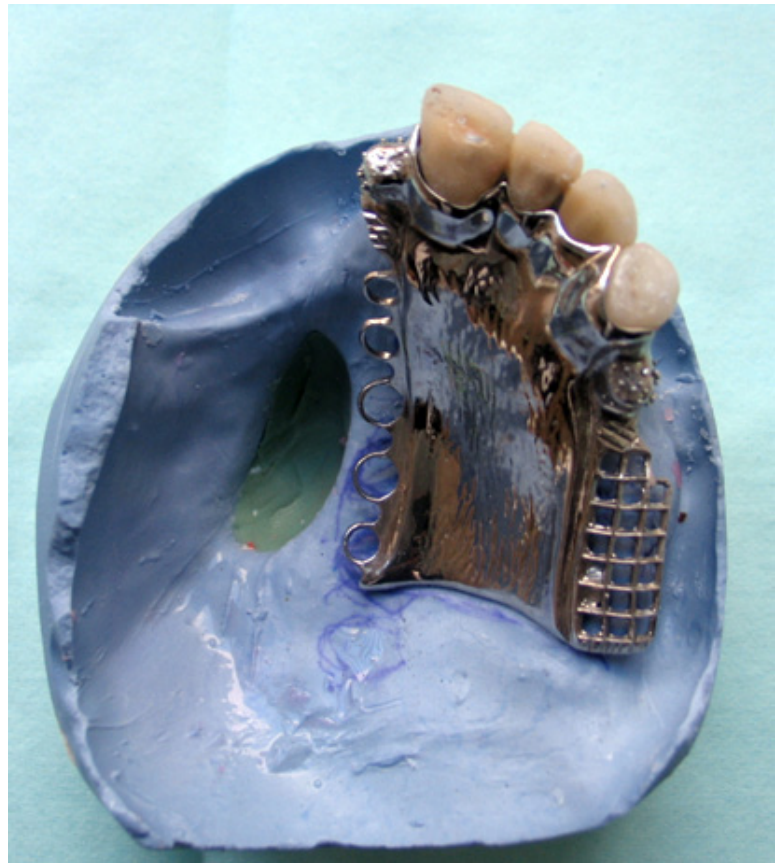

Figure 3. The obturator framework on master modal.

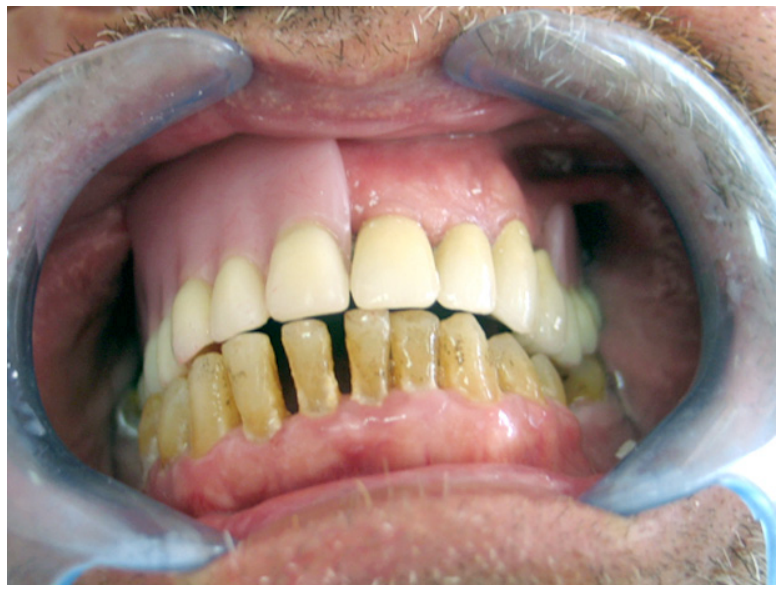

Figure 5. Frontal view of the prosthesis in occlusion. 
premolar, left first molar, left second molar and right first and second molars) (Figure 6). At the request of the patient, the obturator framework was designed with attachments instead of buccal clasps. The treatment objectives included separation of the nasal and oral cavities, restoration of the mid-facial contour and improved speech functions through the provision of a full complement of maxillary anterior teeth.

The right first molar, left canine and left second premolar adjacent to the defect area were restored using metal-ceramic restorations.

Direct retention was provided by resilient extracoronal attachments attached to the mesial surfaces of the right first molar and left first premolar, and the palatinal surfaces were milled. Double Akers clasps on the framework were attached to the right first molar and second molar abutments to provide additional retention. Multiple rests were placed on the restorations to improve stability and provide added support for the prosthesis (Figure 7). Clinical and laboratory procedures were performed as in the case described above a non-hol-

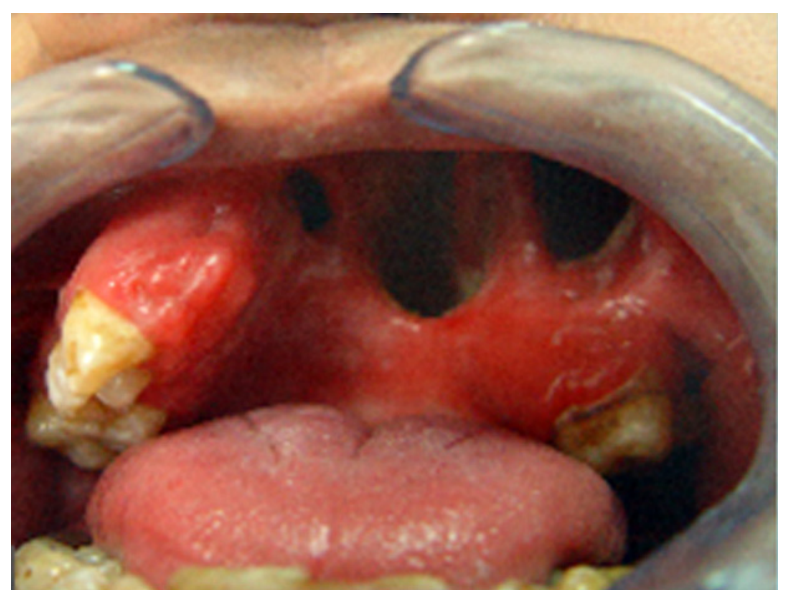

Figure 6. Intraoral conditions prior to prosthetic treatment.

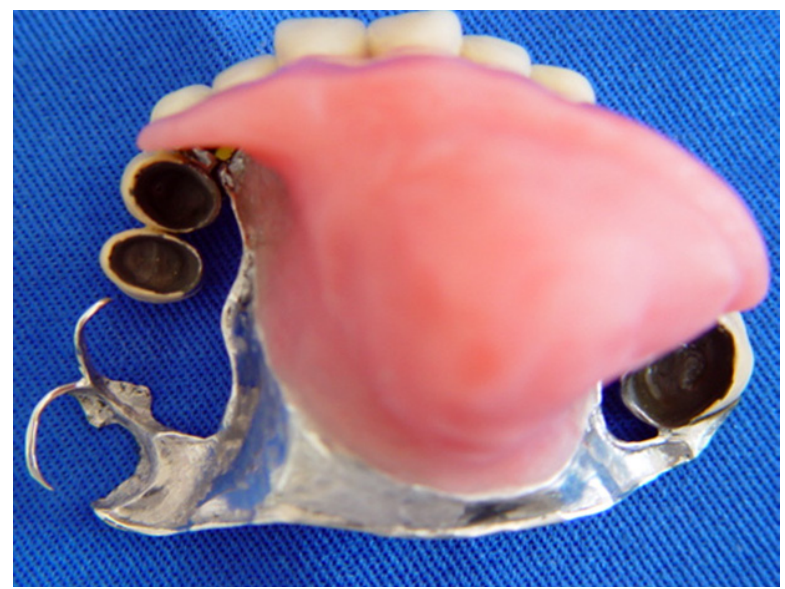

Figure 8. Processed prosthesis. low obturator was designed and delivered to the patient (Figure 8-9). Treatment was completed to the aesthetic and functional satisfaction of the patient, who has been using his prosthesis for 2 years with no complaints. The plastic segment of the prosthesis has been changed twice during this time due to deformation of the plastic segment.

\section{DISCUSSION}

The conventional removable obturator framework design uses various clasps as retention components. 14,17,18 Increasing retention often requires deepening the dental undercut or increasing the supra bulge. ${ }^{22,23}$ Clasps have a low capacity for retention, and plastic deformation caused by cycles of insertion/removal may also lead to a rapid loss in retention that results in air and liquid leakages as well as discomfort. ${ }^{24}$ In some cases, precision attachments may be very useful. Although additional laboratory procedures and resulting increases in costs associated with attachments represent a disadvantage, ${ }^{25}$ nylon attachments are fairly economical, easily replaced, and reduce

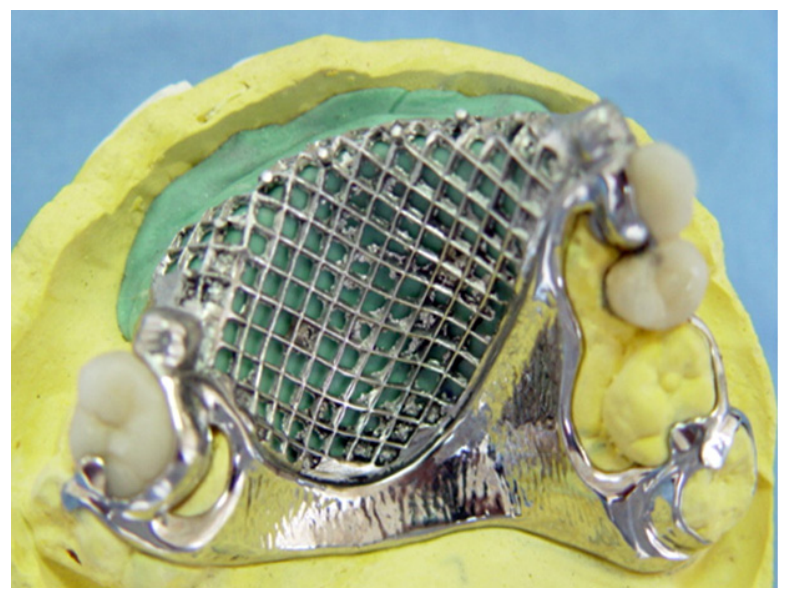

Figure 7. The obturator framework on master modal.

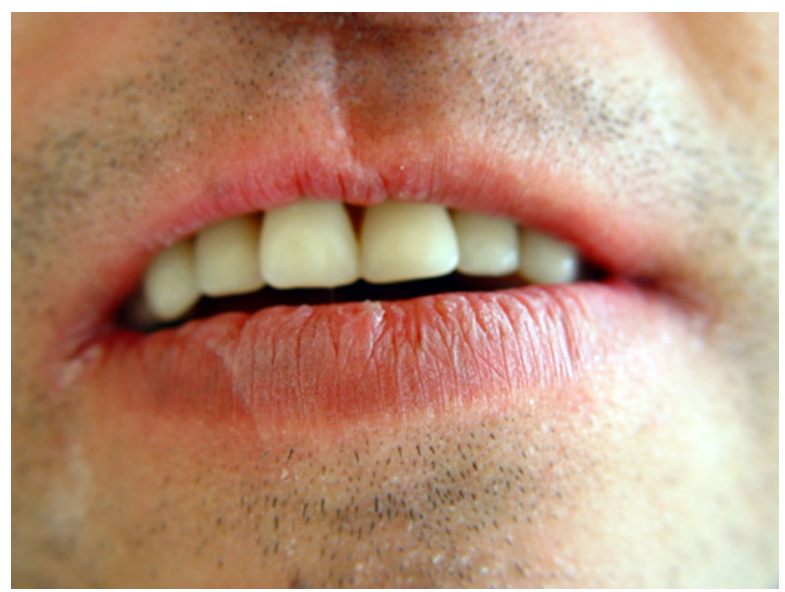

Figure 9. Final appearance with prosthesis in place.

\section{April 2012 - Vol.6}


receptacle wear. For the cases described here, resilient extracoronal ball attachments represented an easy alternative that involved changing the mechanism's retentive nylon caps (female component). ${ }^{26,27}$

The residual maxillary form lie, amount and contour of the remaining palatal shelf, height of the residual alveolar ridge, configuration and size of the defect, availability of undercuts) affects the degree of obturator movement. The position and periodontal status of abutment teeth are critical factors that contribute to the absorption of stress generated by functional movement of the obturator prosthesis and play an essential role in retaining and stabilizing the prosthesis. ${ }^{11}$

Attachments need to be resilient to accommodate obturator movement and reduce the stress on abutment teeth. ${ }^{1,20,25}$ If the defect is large and some or all of the remaining teeth are weak, extra coronal retainers should be used. ${ }^{20}$ Fixed splinting of some or all of the remaining teeth may be indicated in order to distribute the stresses directed at the primary abutment teeth. ${ }^{5}$ Rest seats should be prepared on the abutments adjacent to the extracoronal attachments to direct the forces along the abutment axes and reduce wear on the attachment. ${ }^{20}$ In the first case described here, although the defect was not overly large, in view of the fully dentulous opposing jaw, a resilient-type obturator was constructed in order to decrease stress on the patient's remaining teeth related to obturator movement. In the second case described here, the choice of a resilient-type obturator was considered appropriate based on the patient's fully dentulous mandible as well as the large area of the defect.

In addition to attachments, osseointegrated implants represent another new alternative for oral rehabilitation in patients with partial and total maxillectomies. ${ }^{29,30}$ Osseointegrated implants are commonly used in both the defect and nondefect sides of the maxilla. In addition to providing better support and retention for the prosthesis, osseointegrated implants are able to reduce prosthesis movement and encourage axial loading of the implant. Therefore, a combination of fixed implant supported and removable prostheses can be considered as an alternative. However, in cases reported on here, osseointegrated implants were not preferred since both patients re- jected to receive implant surgery due to financial, social and psychological reasons.

\section{Acknowledgement}

Authors thank Deborah Semel for her editorial assistance.

\section{REFERENCES}

1. Roumanas ED, Nishimura RD, Davis BK. Clinical evaluation of implants retaining edentulous maxillary obturator prostheses. J Prosthet Dent 1997;77:184-190.

2. Sharma AB, Beumer J. Reconstruction of maxillary defects: the case for prosthetic rehabilitation. J Oral Maxillofac Surg 2005;63:1770-1773.

3. Borlase G. Use of obturators in rehabilitation of maxillectomy defects. Ann R Australas Coll Dent Surg 2000;15:75-89.

4. Ducic Y. An effective, inexpensive, temporary surgical obturator following maxillectomy. Laryngoscope 2001;111:356358.

5. Curtis TA, Beumer J. Restoration of acquired hard palate defects: etiology, disability, and rehabilitation. In: Beumer J, Curtis TA, Marunick MT, editors. Maxillofacial rehabilitation: prosthodontic and surgical considerations. 1st ed. St Louis: Ishiyaku Euro-America; 1996. p. 225-284.

6. Okay DJ, Genden E, Buchbinder D, Urken M. Prosthodontic guidelines for surgical reconstruction of the maxilla: A classification system of defects. J Prosthet Dent 2001;86:352-363.

7. Etienne OM, Taddei CA. Use of bar-clip attachments to enhance the retention of a maxillofacial prosthetic obturator: a clinical report. J Oral Rehabil 2004;31:618-622.

8. Nekora- Azak A, Evlıoglu G, Ozdemir-Karatas M, Keskin $\mathrm{H}$. Use of biofunctional prosthetic system following partial maxillary resection: a clinical report. $J$ Oral Rehabil 2005;32:693-695.

9. Hasanreisoğlu, U, Gürbüz A, Belgin E. Speech intelligibility in various types of obturators constructed after maxillary resections. Ankara Univ Hekim Fak Derg 1989;16:77-86. (Turkish)

10. Devlin H, Barker GR. Prosthetic rehabilitation of the edentulous patient requiring a partial maxillectomy. J Prosthet Dent 1992;67:223-227.

11. Keyf F. Obturator prostheses for hemimaxillectomy patients. J Oral Rehab 2001;28:821-829.

12. Ortegon SM, Martin JW, Lewin JS. A hollow delayed surgical obturator for a bilateral subtotal maxillectomy patient: a clinical report. J Prosthet Dent 2008;99:14-18.

13. Gürbüz A, Hasanreisoğlu U. Clinical comparison of different types of obturators constructed after maxillary resections. Ankara Univ Hekim Fak Derg 1990;17:103-108. (Turkish) 
14. Parr GR, Tharp GE, Pahn AO. Prosthetic principle of the framework design of maxillary obturator prostheses. $J$ Prosthet Dent 1989;62:205-212.

15. Goiato MC, Pesqueira AA, Silva CR, Filho HG, Santos DM. Patient satisfaction with maxillofacial prosthesis: literature review. J Plast Reconstr \& Aesthet Surg 2009;62:175-180.

16. Brignoni R, Dominici JT. An intraoral-extraoral combination prosthesis using an intermediate framework and magnets: a clinical report. J Prosthet Dent 2001;85:7-11.

17. Aramany MA. Basic principles of obturator design for partially edentulous patients. Part I: Classification. J Prosthet Dent. 1978;40:554-557.

18. Aramany MA. Basic principles of obturator design for partially edentulous patients. Part II: design principles. J Prosthet Dent 2001;86:562-568

19. King GE, Martin JW. Cast circumferential and wire clasps for obturator retention. J Prosthet Dent 1983;49:799-802.

20. Brudvik JS, Taylor TD. Resin bonding for maxillofacial patient. In: Taylor TD, editor. Clinical maxillofacial prosthetics. Chicago: Quintessence; 2000.p.53-62.

21. Gay WD, King GE. Applying basic prosthodontic principles in the dentulous maxillectomy patient. $J$ Prosthet Dent 1980;43:433-435.

22. Johnson DL. Retention for a removable partial denture. $J$ Prosthodont 1992;1:11-17.

23. Alfonso C, Toothaker RW, Wright RF, White GS. A technique to create appropriate abutment tooth contours for removable partial dentures. J Prosthodont 1999;8:273-275.

24. Vallittu PK, Kokkonen M. Deflection fatique of cobalt-chromium, titanium, and gold alloy cast denture clasp. J Prosthet Dent 1995; 74:412-419.

25. Grossmann Y, Madjar D. Resin- bonded attachments for maxillary obturator retantion: clinical report. J Prosthet Dent 2004;92:229-232.

26. Williamson RT. Removable partial denture fabrication using extracoronal resilient attachments: A clinical report. $J$ Prosthet Dent 1993;70:285-287.

27. Sigurgeirsdottir E, Minsely GE, Rothenberger SL. Incorporation of an ERA attachment for obturator framework design: a clinical report. J Prosthet Dent 2002;87:477-480.

28. Koyama S, Sasaki K, Inai T, Watanabe M. Effects of defect configuration, size, and remaining teeth on masticatory function in post-maxillectomy patients. J Oral Rehab 2005;32:635-641.

29. Mentag PJ, Kosinski TF: Increased retention of a maxillary obturator prosthesis using osseointegrated intramobile cylinder dental implants: a clinical report. J Prosthet Dent 1988;60:411-415.
30. Izzo SR, Berger JR, Joseph AC, et al: Reconstruction after total maxillectomy using an implant retained prosthesis: $A$ case report. Int J Oral Maxillofac Implants 1994;9:593-595.

\section{April 2012 - Vol.6}

